\title{
AIDS Puzzle was Solved
}

\author{
Makarov $S^{*}$
}

Independent researcher, Riga, Latvia

*Corresponding author: Makarov S, Independent researcher, Riga, Latvia, E-mail: segrim@bas.lv

Citation: Makarov S (2015) AIDS Puzzle was Solved. J Aids Hiv Infec 1(2): 202. doi: 10.15744/2454-

499X.1.202

Received Date: June 17, 2015 Accepted Date: July 06, 2015 Published Date: July 08, 2015

\begin{abstract}
Author discovered the main law of nature - the Law of World Harmony. Applying this law to the problem of AIDS, the author has solved the problem. AIDS, according to the author, is not infectious disease, but it is a disease of the "chain reaction" type. The author revealed the mechanism of the AIDS parasitic program working, described the methodology for AIDS accurate diagnostics and offered the effective way of his full treatment with the help of hyperthermia. In 2012 the author published a monograph, where described the patent search and proved the author's world priority for the method of AIDS treatment on May 22, 1989.
\end{abstract}

Keywords: Law of World Harmony; AIDS; Human immune defense system; Parasitic program; T-helpers; Thymus gland

I am a scientist and theorist. More than 25 years I have devoted to AIDS problem. In this area, I have received the real revolutionary result: the problem was completely solved by me. About how it was, I want to write in this article.

May 8, 1989 I was able to formulate the most universal law of nature, the need for which, in particular, was featured on page 120 of the book [1].

"The World Harmony Law" is a serious discovery, however, it goes beyond any of the specific sciences. I became able to open this law as a result of to in-depth analysis of a number of sciences (mainly physics, mathematics and biology) and axioms of dialectic materialism. For creating a clear statutory language I spent eight years in the purposeful work and used the "Occam's Razor".

Since this is the universal law of nature, it could well be obtained from the analysis of any of the existing sciences, as well as from the sphere of art. The universality of the law allow to use it in any kind of science, in any form of art, as well as for contacts with other civilizations (of course, not in the form of text).

Full (Double-Symmetric) Formulation of the Law of World Harmony

("Logical Nature's metric" or "Makarov's Nous-law”)

A real [ideal (virtual)] existence of two formations of certain type and a real [ideal (virtual)] opportunity of their intertransitions (transmutation) inevitably give birth to real [ideal (virtual)] formations of new two types, namely:

- Formation of higher type, which is a generalization for the set of formations of the initial type ("SYNTHESIS" - to this direction the volume of information increases, but entropy decreases).

- Some formations of lower type, which are characterized by the circumstance, that each of formations of initial type self is a generalization for set formations of lower type ("DECAY" - to this direction the volume of information decreases, but entropy increases).

For hundreds of years, many researchers have sought to find the "most important law governing the whole of nature." But all their attempts led them either to death or to a madhouse. This basic law of nature nobody formulated before me. More details about this law can be found in the chapter "The World Harmony Law" on my website http://hammer.bas.lv/. I registered at the notary the formulation of the text of this law in May 11, 1989.

Having found the universal law, I immediately wanted somewhere to use it. To test the effectiveness of the law, I chose the most important, as I thought, the problem of mankind - the problem of AIDS. In a Soviet journal I found a good article about AIDS [2] and became to analyse it. In this analysis, I was guided by the famous dictum: "Seek the beginning of the problem and you will understand much." As a result of a deep analysis of the problem, I came to the following conclusions:

1. The first person got AIDS by sexual contact with a monkey.

2. AIDS is transmitted between people in the form of chain reaction along the path of live blood (in vagina or rectum).

3. AIDS develops as a result of parasitic program working in person's blood, this program does not have a material carrier.

4. No one virus not participates in arising and spreading of AIDS.

5. Work of the immune defense system of the person consists not in the destruction of alien viruses, bacteria, fungi, protozoa, etc. (as is currently officially considered to be), but in binding them with the help of specific program with lymphocytes, e.g., T-helper cells (known as lymphocytes CD4), followed by discharge of the product that regard from the body (e.g., in the form of diarrhea). 
6. Parasitic program replaces the human immune defense system, it connects pairs of T-helper cells among themselves with extracting them out of human's body.

7. Parasitic program of AIDS is not visible under the microscope, so virologists efforts to combat it are useless.

8. Although the parasitic program cannot be seen under a microscope, the results of its work (T-helpers associated into pairs) are seen through a microscope, this allows us reliably diagnose AIDS.

9. Full hyperthermia of human's body up to 42-44 degrees Celsius allows to sever the paired T-helpers (if they yet were not removed from the body), and return them to the body's defense. As a result, AIDS stops.

10. If the thymus gland in human's body works good then it produce the quantity of T-helpers, which is enough and for

"subsistence of parasitic program" and the fight against external infections. As a result, a person can live without any treatment for a long time.

AIDS is not a contagious disease, it is representative of a new type of disease - "diseases of chain reaction type" (look, for example, [3]). This term was introduced into the theory of medicine by me personally. If you are interested in more details, read them in my monograph [4], chapter no. 6. In this monograph is given the scientific evidences the effectiveness of hyperthermia against AIDS and was held a deep patent search for evidence of my world priority in this regard.

For years, I try to inform the mankind: I have solved the problem of AIDS. Use my solution and do not spend billions of dollars on condoms and on the content of many thousands "of professionals in the fight against AIDS". Eighty Academies of Sciences on my letters to them did not answer anything. Three Nobel Prize winners also did not answer me. Hundreds of journalists have answered me nothing and did not even placed my news into their news roundup.

And all it despite the fact that I have already been published two monographs: [4], in the world scientific journal «World Journal of AIDS» I published the article [5]. Later appeared also Russian version of this article [6].

In medicine I have achieved several significant results, namely:

- Deciphered the true mechanism of the human immune defense system working.

- Deciphered the real mechanism of development of AIDS and discovered that AIDS is not an infectious disease, but the disease entirely new type - the disease of "chain reaction" type.

- Introduced a new section in medicine - "diseases of chain reaction type".

- I found that many types of cancer, as well as several other diseases (multiple myeloma, diabetes...) also are "diseases of chain reaction type".

Did the results I received do not deserve any thanks?

From time immemorial came to us the following method of fraternization. Two men incise their blood vessels on the wrist, and open wounds tightly cuddle up each to other for some time. What is the rationale for this method? Of course, firstly, so the blood represents self as an agent of bio-field (bio-field carrier), then it give a "kinship of souls and bodies".

Secondly, all the "chain reactions" (diseases such as AIDS) instantly move from one organism to another along the road of live blood (this process is similar to burning a track from the gunpowder). In this way, people show each other the full confidence and willingness to die for each other.

The law of world harmony could be applied to very many problems. Its use in the construction, see., Eg, [7,8]. However, I forbade myself to solve any serious problems of mankind (for example, the problem of Ebola or MERS) till the time, when my solution to the problem of AIDS will be officially recognized, I do not like to "thresh over old straw". With the help of their own indifference too many people are trying to convince me that my work and its results are not useful to anybody. We wait and see. We'll all have to be waiting.

\section{References}

1. Sedov E (1982) One formula of the whole world. Knowledge Moscow.

2. Zhdanov VM (1987) AIDS: what do we know about it? Health J 5: 6-7.

3. Makarov S (2015) AIDS is the Disease of Chain Reaction Type. Global J Med Resear.

4. Makarov S (2012) Puzzle with the name AIDS. LAP LAMBERT Acade Publish: 112.

5. Makarov S (2014) The Problem of AIDS May Have Already Solved. World J AIDS.

6. Makarov S (2015) The Problem of AIDS May Have Already Solved. Agency of technical and scientific information.

7. Makarov S (2011) World Harmony Law.

8. Makarov S (2012) Law of World Harmony. Techno-community of Russia. 


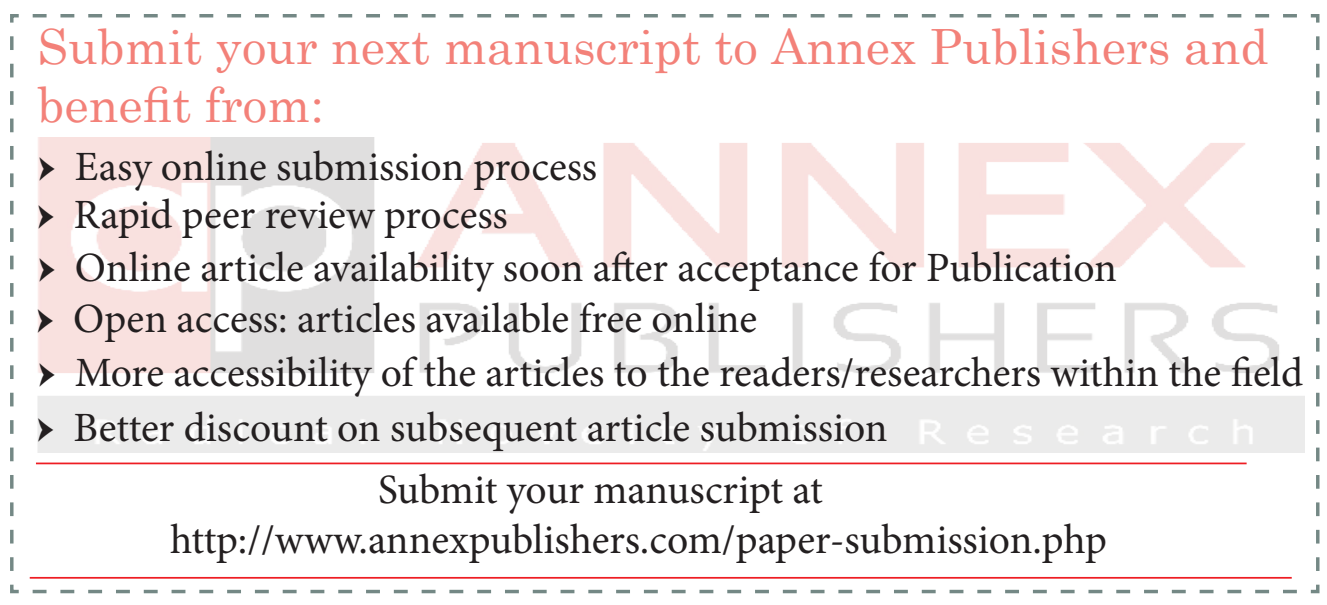

